\title{
Types of Conjugal Networks, Conjugal Conflict and Conjugal Quality
}

\author{
Eric Widmer, Jean Kellerhals and René Levy
}

This article considers how various configurations of network characteristics affect conjugal quality. To investigate this issue, we use data from a large survey on conjugal functioning, based on 910 married couples with co-resident children living in Switzerland. Using reports from both male and female partners, we first empirically define six types of conjugal networks. We then explore the extent to which those types affect conjugal conflict and conjugal quality, making a distinction between direct, indirect and buffering effects. We find that network types have significant direct and indirect effects on conjugal quality but no significant buffering effect. We further discuss the importance of our results for understanding the functioning of contemporary couples within larger relational contexts.

\section{Introduction}

Dyadic relationships of the nuclear family, such as those between husbands and wives, do not exist in a vacuum and scholars have underlined how important it is to take into account the social networks in which they are embedded (Bott, 1957; Burger and Milardo, 1995). Capturing the most central and relevant features of social networks for conjugal functioning is, however, not straightforward. Most research interested in the effects of social networks on conjugal interactions has focused on specific variables, such as network composition (Burger and Milardo, 1995), network interference (Klein and Milardo, 2000), spouses' network overlap (Stein et al., 1992; Bryant and Conger, 1999), network transitivity (Widmer, 1999), or perceived support from the network (Cohen and Wills, 1985).

These studies have provided valuable information on couple functioning within larger contexts. They can be complemented by considering those features as parts of structural and functional configurations, or types, of conjugal networks. A typological approach to social groupings stresses the interrelations existing among group features. It assumes that structural and functional variables which define the relational contexts of couples may have quite different consequences by virtue of their being embedded in specific configurations (Broderick, 1993). Thus, considering patterns of network characteristics, rather than network characteristics independently from one another, may provide new insights on conjugal functioning in broader relational contexts. Based on data drawn from a large representative sample of couples living in Switzerland (Widmer et al., 2003), this article constructs a multi-faceted typology of conjugal networks and measures its association with conjugal conflict and conjugal quality.

\section{Structural and Functional Characteristics of Support Networks}

When studying the effects of social support, attention has been especially directed to several specific structural and functional characteristics of social networks (Cohen and Wills, 1985). 
First, scholars have distinguished between interactional, material, and psychological functions of networks. A network can provide strong emotional support without necessarily providing strong financial support. Also, correlations between frequency of interactions and psychological import of network members are far from one, suggesting that these are independent dimensions of social networks (Milardo, 1989; Surra and Milardo, 1991). In general, psychological components of networks are found to be much more influential on individual outcomes than interactional components (Cohen and Wills, 1985).

Second, there is evidence that relations with different classes of network members vary systematically in terms of types of social exchange. As a rule, closely related relatives provide a greater degree of support, and do so in a wider variety of domains, than friends and neighbours; friends are more active in terms of companionship (Coenen-Huether et al., 1994; Wellman and Wortley, 1989). Because of these variations, it has been hypothesized that network composition (friends versus relatives) has an effect on conjugal outcomes. In an exploratory study, Burger and Milardo (1995) found, for instance, that husbands report greater marital conflict and ambivalence in conjugal relationships when wives interact frequently with friends rather than with relatives.

Third, two persons living in a couple may have quite different and unequally supportive networks, since networks show various degrees of overlap (Stein et al., 1992). It has been hypothesized that the spouse with greater support from his or her network, does better than the other (Baumgartner, 1993). Alternatively, network types might be more influential for women than for men as women are more involved in kinship connections: they report larger networks of relatives and greater contact and exchange with them (Coenen Huther et al., 1994; Johnson, 2000). The centrality of women in the Western kinship system (Adams, 1970) may be associated with a greater sensitivity to relationships with relatives than that of men. Indeed, earlier research provides some indication of gender differences in the influence of social networks, perceptions of relationship approval from family members being more influential for women than for men in predicting the long-term continuation of premarital relationships (Sprecher and Felmlee, 1992). Furthermore, the order of influence of network factors on conjugal satisfaction might be different for men and women, although empirical evidence is rather tangential in this regard (Bryant and Conger, 1999). In any case, it is important to examine network effects for men and women separately.
Empirical work suggests that features of social networks are not independent of each other but are rather organized in discrete, qualitatively distinct, configurations, with emergent properties which might well have different consequences for couple functioning. For instance, support provided by the network might have quite different consequences depending on whether it is or is not perceived as interference within couple functioning (Holman, 1981; Johnson and Milardo, 1984). Also, available support has a quite different meaning depending on whether it comes from friends or relatives (Coenen-Huther et al., 1994). Only a typological approach can take into account these various influences and their complex interactions. Despite the fruitful contributions of the typological approach to the understanding of family functioning (Kantor and Lehr, 1975; Reiss, 1981; Olson et al., 1988; Olson and McCubbin, 1989), typologies of conjugal networks are scarce, most of the time unidimensional, and mostly based on convenience samples or case studies. Most of them have not been associated with conjugal functioning (for an exception, see Stein et al., 1992) or have failed to show convincing evidence that such an association exists (Bott, 1957). Small sample sizes, unidimensionality of network constructs, and insufficient or absent measures of conjugal functioning are recurrent problems in research on the effect of types of conjugal networks on conjugal functioning.

\section{Buffering, Direct and Indirect Effects of Conjugal Networks}

Research shows that individuals who perceive that extensive support is available to them if they need it, do better than others on a variety of outcomes. Two different models account for the effect of support networks on individual outcomes (Cohen and Wills, 1985). One model states that support is related to positive outcomes only for subjects under stress. Thus, support networks have a buffering effect (Kaplan et al., 1977) because they protect subjects from the negative influence of stressful events or situations. Quite differently, the main effect model assumes that support networks can have an effect on individuals irrespective of whether persons are under stress or not (Cohen and Wills, 1985). In this case, support networks influence personal outcomes either through a direct effect on outcomes, or because they are associated with a differential exposure to stressors (indirect effect), not because of a larger insensitivity to stressors for supported individuals (buffering effect). 
This theoretical framework was developed initially to deal with the effects of support networks on individual outcomes, either psychological or physiological. However, it is also relevant to research where stressors and outcomes refer to conjugal relationships. In this regard, a distinction was made between conjugal quality, defined as an overall feeling toward the marriage (either positive or negative), and conjugal conflict, defined as the processes that contribute to this feeling (Finchman and Bradbury, 1987). The distinction between conjugal conflict as a stressor and conjugal quality as an outcome is valuable since it enables researchers to conceptualize the effects of conjugal networks on conjugal quality with reference to the 'buffering-main effect' hypotheses (Cohen and Wills, 1985).

The hypothesis of an indirect effect of conjugal networks on conjugal quality states that couples with strong networks develop fewer conjugal problems, have fewer arguments, and have better coping strategies because their relatives and friends provide alternate communication channels, a moderating influence, and some guidance in coping strategies. In other words, strong conjugal networks make conjugal conflict less likely to occur and therefore decrease the probability of couples showing poor conjugal quality. The hypothesis of a direct effect of conjugal network is based on the assumption that cohesive and supportive conjugal networks do not affect conjugal conflict but benefit conjugal outcomes because they provide spouses with a general feeling of self-worth and a positive self-image that help them deal with their relationships. As for the buffer hypothesis, it predicts that sensitivity of conjugal quality to conjugal conflict varies depending on the type of network. More precisely, it states that the more cohesive the network is, the less detrimental to conjugal quality is conjugal conflict. In other words, the responsiveness of conjugal quality to conflict is hypothesized to be lower in couples with a supportive network than in couples with non-supportive networks.

Although strong evidence supports a positive effect of network embededness on individual outcomes, one should note that things might be different for conjugal quality. Some empirical research suggests that effects of support networks on conjugal quality is curvilinear (Holman, 1981), i.e. extremely cohesive networks might be detrimental to conjugal functioning. The interference model (Johnson and Milardo, 1984; Julien et al., 1994) states that social networks and conjugal relationships might actually compete. Developing relationships creates anxiety in social networks because time and energy devoted to other relationships are challenged. Thus, social network members may try to hold or regain some influence on ego by interfering in his or her conjugal relationships. In this perspective, strong networks may not buffer the effects of conjugal conflict but may actually increase them, because the emergence of conjugal problems opens doors to further interference from the network members in the couple's relationships.

Lastly, effects of networks on conjugal quality may well be spurious because of a selection bias, people with poor psychological well-being being at risk of both high conjugal conflict and poor or absent relationships with network members (Cohen and Wills, 1985; Booth and Amato, 1991). Therefore, one should control for psychological distress when dealing with network effects on conjugal functioning.

The present research explores the ways in which various network dimensions that have been found to be significant for conjugal functioning in previous research can be summoned in distinct network types. It then considers how those types fit within the two classical theoretical models dealing with support, by testing a buffering effect hypothesis and a main effect (either direct or indirect) hypothesis of network configurations on conjugal quality, with a control for a possible spurious effect associated with psychological distress of respondents.

\section{Data}

The data used in these analyses are drawn from the study 'Social Stratification, Cohesion and Conflict in Contemporary Families', a large and representative survey of married and unmarried couples living in Switzerland. Conducted in 1998, the study's primary goal was to examine how cohesion and conflicts in couples are influenced by partners' social status and position in the life course. The sample for the project was drawn randomly using a non proportional stratified design based on the three major linguistic areas of Switzerland. A computer-assisted telephone survey questionnaire was translated in the three major idioms of Switzerland (German, French and Italian). The data collection took place between October 1998 and January 1999. The subsample considered here includes 910 married couples with co-resident children, from the three linguistic areas mentioned above. In each couple, both spouses were interviewed separately. On most questions, both partners had to provide an answer. Overall, the sample has demographic features very similar to those of other recent surveys and micro-censuses on households and families in Switzerland (OFS, 1998). 


\section{Measures}

Three dimensions are central in this research: features of conjugal networks, conjugal conflict, and conjugal quality.

\section{Features of conjugal networks}

Based on results from previous analyses of conjugal networks (Milardo, 1988; Surra, 1988; Wellman and Wortley, 1989; Coenen-Huther et al., 1994), we focus on five dimensions of conjugal networks: size, composition (friends or relatives), activity (frequency of contacts), support available (amount and type), and the overall cohesiveness of the network (strong or weak cohesiveness, and interference of the network in the couple functioning). Available support was used instead of activated support, as various studies have shown that it has much more impact on individual outcomes (i.e. Wethington and Kessler, 1986). For each couple information was collected independently from the man and woman, so that we had measures for each spouse's network.

Network size is measured by asking respondents how many members of the kinship and friendship network live in their geographical area (no more than 20-30 minutes driving). Forty-two per cent of men and 41 per cent of women have four or more relatives living in the area. Sixty-eight per cent of respondents of both genders have three or more friends close by.

Network activity is measured by the frequency with which each partner meets with relatives and friends. Sixty-four per cent of men and 66 per cent of women meet with relatives at least once every two weeks. Sixtyeight per cent of men and 58 per cent of women meet with friends at least once a week.

Network support available is measured by asking whether respondents can count on the support of their families and friends in the event of a serious problem. Emotional support is the most readily available: 65 per cent of men and 76 per cent of women think that they would get such support if needed. Domestic support is also present: 52 per cent of men and 53 per cent of women say that they can rely on important domestic help from relatives or friends if needed. Similar results were found for financial support (47 per cent of men and 48 per cent of women say that they can count on important financial support from their network if needed).

Cohesiveness of the kinship network is measured with two indicators: the overall quality of interpersonal relationships in the kinship network and the interference of the kinship network in the couple functioning. The first question read: 'How would you best describe the relationships among your relatives?. Responses were: (a) a close, affectionate and united family; (b) a family where people get along with each other but where relationships are rather distant; (c) a family characterized by indifference; (d) a family characterized by hostility and conflicts. Sixty-two per cent of women and 50 per cent of men say that they belong to a close, affectionate, and united family. Network interference was measured by a single item, asking respondents whether or not they feel controlled by their relatives in their conjugal life. Twenty-two per cent of women and 18 per cent of men feel that their couple is controlled by their family.

\section{Conjugal Conflict}

Conjugal conflict was measured by three constructs: conjugal problems, conjugal disagreements, and coping strategies. A sequence of Principal Component Analyses was performed on the matrix of interitem correlations with a varimax rotation. This analysis confirmed that our theoretically defined constructs were empirically distinct, as each of the three constructs was identified by a different factor. These measures were constructed at the couple level, by including responses from both men and women.

For conjugal problems, each partner had to indicate whether or not his or her couple was currently experiencing a list of 19 problems, such as a serious communication inability, problems in dealing with the partner's personality, sexual problems, infidelity, task sharing problems, etc. Responses from both spouses were combined into a single measure with a Cronbach's Alpha of 0.73.

Conjugal disagreements were measured using a set of four indicators describing the frequency of open conjugal disagreements, the frequency of covert conjugal disagreements, the severity of those disagreements, and the ease with which they were overcome. Both spouses graded those items and their responses were added up in a single measure, with a Cronbach's Alpha of 0.78.

Poor coping strategies were measured using a set of nine items which captured the way partners act toward each other when a serious problem occurs. They can put each other under pressure, threaten each other, or, alternatively, negotiate, listen, etc. Cronbach's Alpha is 0.70 .

\section{Conjugal Quality}

Conjugal quality was measured with three indicators: conjugal negative affects, conjugal dissatisfaction, and conjugal instability. As conjugal quality refers to a subjective 
assessment of conjugal relationships, scores of both partners were considered separately.

Conjugal dissatisfaction was measured by a single question asking: 'Overall, how would you rate your couple? Are you going along.... Responses range from 'very well' to 'really bad'. Fifty per cent of women and 47 per cent of men did not choose the response 'very well'. Conjugal instability was measured by asking respondents whether or not they had already thought about separating, which was the case for 22 per cent of men and 34 per cent of women.

Negative conjugal affects were measured by a set of nine items that asked respondents to grade the emotional climate that prevailed in their couple. Negative as well as positive items were included in the scale. Examples are: 'we laugh, we are happy', 'we are in love', or, alternatively, 'we are irritated', 'we are sad, unhappy'. Responses range from 'always true' to 'always wrong'. Cronbach's Alpha was 0.78 for women and for men. In order to have a dichotomous variable, we split the scale at the median.

\section{Control Variables}

When measuring the mediating effect of conjugal networks between conjugal conflict and conjugal quality, we controlled for the effect of several socio-demographic variables which are significantly associated with family issues: duration of union, number of children, average age of partners and household income (each included as a control variable). We also controlled for psychological distress by a set of six items, that asked respondents whether they presently feel sad, lonely, helpless, tired, nervous and whether or not they have unexplained somatic troubles (Radloff, 1977). Cronbach's Alphas were 0.74 for men and 0.75 for women.

\section{Results}

We first construct six types of conjugal networks. Then, we show their associations with conjugal conflict and conjugal quality using bivariate statistics. Finally, we investigate which effect (direct, indirect or buffering effects) is more likely to explain those associations using several logistic regression models.

\section{A Network Typology}

In order to capture the interrelations among network features, which were measured at the nominal or ordinal levels in this study, we first run a multiple correspondence analysis (Greenacre, 1983, 1993; Weller and Romney,
1990). We then derive six distinct network types from multiple correspondence analysis scores, using cluster analysis (Lebart et al., 1997). Cluster analysis makes it possible to go beyond the effects of specific dimensions of networks on conjugal quality and to find holistic configurations of network dimensions. ${ }^{1}$ It has already been used to construct typologies of networks (Stein et al., 1992; Coenen-Huther et al., 1994). To determine the number of network profiles, we examine a sequence of hierarchical cluster analyses based upon Ward's method of clustering on the first four axes of the correspondence analysis (Lebart et al., 1997). Instead of partitioning the observations into some predetermined number of clusters in a single step, this hierarchical procedure produces step by step splits (Everitt, 1993). Ward's method minimizes within-cluster variance and thus produces good estimates of cluster groupings. Most of the distance reduction occurs at or before the fifth splits. Thus, the couples can be adequately described as belonging to only six clusters. Profiles of final groupings are presented in Table 1.

Couples with sparse networks (18 per cent of the sample) are characterized by weak ties with friends and relatives, for both partners. The network is rather small and contacts with friends and relatives are sparse; support is not readily available. Interference of the network is very low, as is the overall quality of relationships in the network.

Couples with friendship networks (15 per cent of the sample) strongly invest in their friendship ties, whereas their kinship ties are almost non-existent. Those couples do not have a great number of relatives living close to them and they do not interact very often with them. Their family is not considered warm and supportive, but neither is it interfering. Support is available, most likely from friends. Again, both partners have very similar network profiles. One exception is that men have a smaller and more passive kinship network than women.

In couples with patricentric networks (18 per cent of the sample), men have a much larger number of relatives and friends than women do. They meet with their relatives and friends more often and can get support from them much more easily than women do. These couples can be described as asymetrical or unicentric, as one partner's network is predominant. Note, however, that quality of family relationships is the same on both sides.

Couples with matricentric networks (21 per cent of the sample) stand in sharp contrast to couples with patricentric networks. In their case, women have a much larger and much more active network than men, both in terms of relatives and friends. Support is more readily 


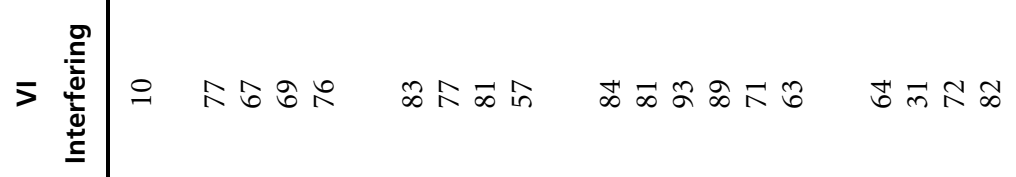

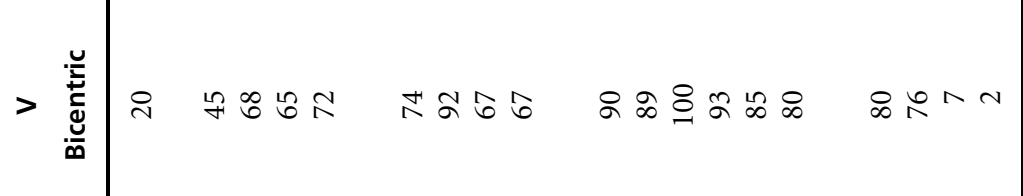

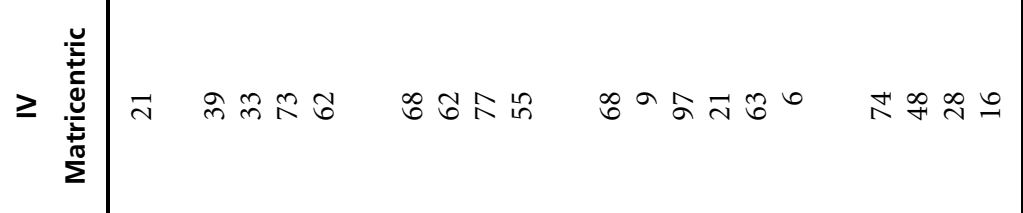

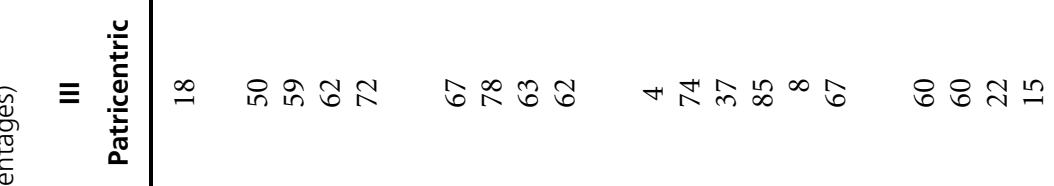

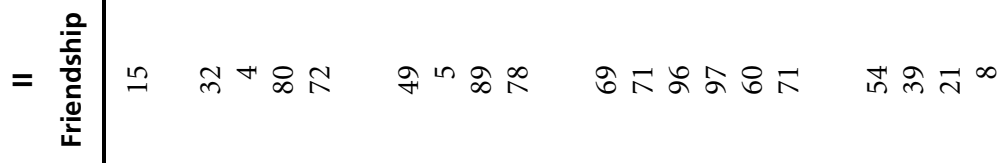

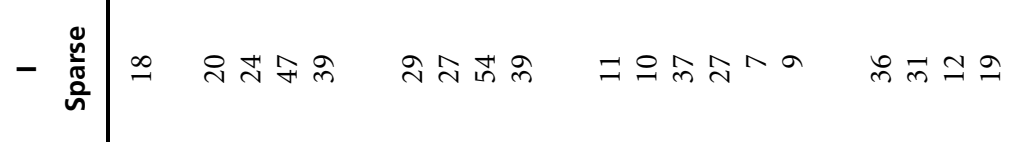

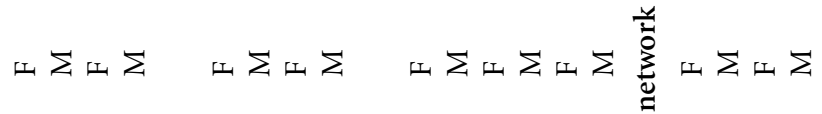

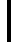


available for women than for men, and the overall quality of relationship among their relatives is significantly higher.

Couples with bicentric networks (20 per cent of the sample) are characterized by strong kinship and friendship ties for both partners, who have large number of friends and relatives around and frequent contacts with them. Both partners would get support in case of need. Family relationships are seen as strong and warm by both of them. Couples with interfering networks (10 per cent of the sample) are similar to couples with bicentric networks with regard to the strength of support. However, there is a strong feeling of being controlled by the kinship network, especially for women. Family relationships are much more often considered as not warm than in bicentric networks.

Cluster analysis revealed six contrasting network types. There are great variations among those types, in terms of strength of relationships (high available support versus low available support); composition of the network (friends versus relatives); lateralization of the network (bicentric versus unicentric) and gender (women side versus men side).

\section{Network Types, Conjugal Problems, and Conjugal Quality}

Are network types significantly associated with indicators of conjugal conflict and conjugal quality? Based on a set of linear and logistic regressions, Table 2 considers how indicators of conjugal functioning vary depending on network type. Sparse networks are chosen as the reference category.

First, conjugal network types correlate moderately with two out of the three dimensions of conjugal conflict. Conjugal disagreements do not vary across conjugal network types. Interestingly, however, coping strategies and conjugal problems do vary. Couples with a friendship, bicentric or interfering network cope better than couples with a sparse network. Conjugal problems occur significantly less often in matricentric and bicentric networks. Except for this, conjugal networks have no significant effect on conjugal conflict.

As for the indicators of conjugal quality, all of them are strongly associated with network types. Couples with bicentric networks show significantly fewer negative effects than couples with sparse networks. Table 2 also shows that couples embedded in bicentric networks have much lower signs of dissatisfaction and instability than couples with other types of networks, according to respondents of both genders. Couples with patricentric, matricentric, or friendship networks do not show signi- ficantly lower conjugal dissatisfaction or conjugal instability than couples with sparse networks. Couples with interfering networks also have high levels of negative effects, dissatisfaction and instability. Thus, bicentric networks can be singled out as associated with good outcomes in terms of conjugal quality, compared with other types of conjugal networks.

Responses from men and women are quite similar in most cases. One exception is that women are better off in matricentric networks in terms of conjugal affects, whereas men are better off in friendship networks. Regression coefficients and measures of fit also show that, in general, conjugal quality as reported by women is more sensitive to conjugal networks than conjugal quality as reported by men.

\section{Direct, Indirect or Buffering Effects?}

What are the factors which underline the association between network types and conjugal quality? As couples with unicentric (either patricentric or matricentric), interfering and friendship networks are not significantly different from couples with sparse networks in terms of their associations with conjugal dissatisfaction and conjugal instability (see Table 2), we singled out bicentric networks, in order to include only statistically significant variables in the logistic model (Hosmer and Lemeshow, 1989).

Table 3 presents the results of a logistic regression with conjugal affects regressed on network types and indicators of conjugal conflict. Three models are tested. Model A includes the effect of network types with the control variables. Model B differs from Model A by adding the hypothesized effects of conjugal conflict. Thus, it captures a series of main effects, either direct or indirect (caused by the association between conjugal conflict and network types). In Model C, the buffering effect of conjugal networks is tested as an interaction (Jaccard et al., 1990) between conjugal conflicts and network types.

Model 3A shows that network types have a significant effect on conjugal affects controlling for effects of confounding variables (in particular for psychological distress, where effect is highly significant). This effect is stronger for women than for men. With the inclusion of indicators of conjugal conflict (Model 3B) the network effect decreases. It remains, however, significant for women, but not for men. Interaction terms (Model 3C) are not statistically significant. Further testings of interaction terms (Jaccard et al., 1990; Allison, 1999) confirmed this result. Because of multicolinearity of main effects and interaction terms (Hosmer and Lemeshow, 1989), interaction terms make all direct effects insignificant. 


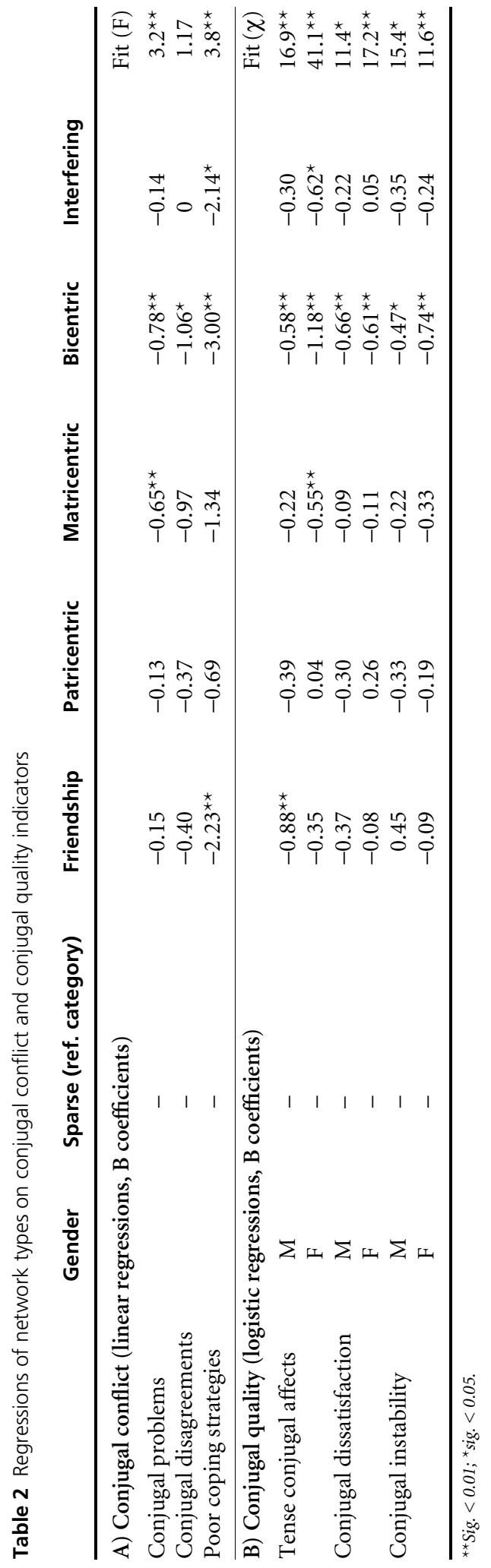




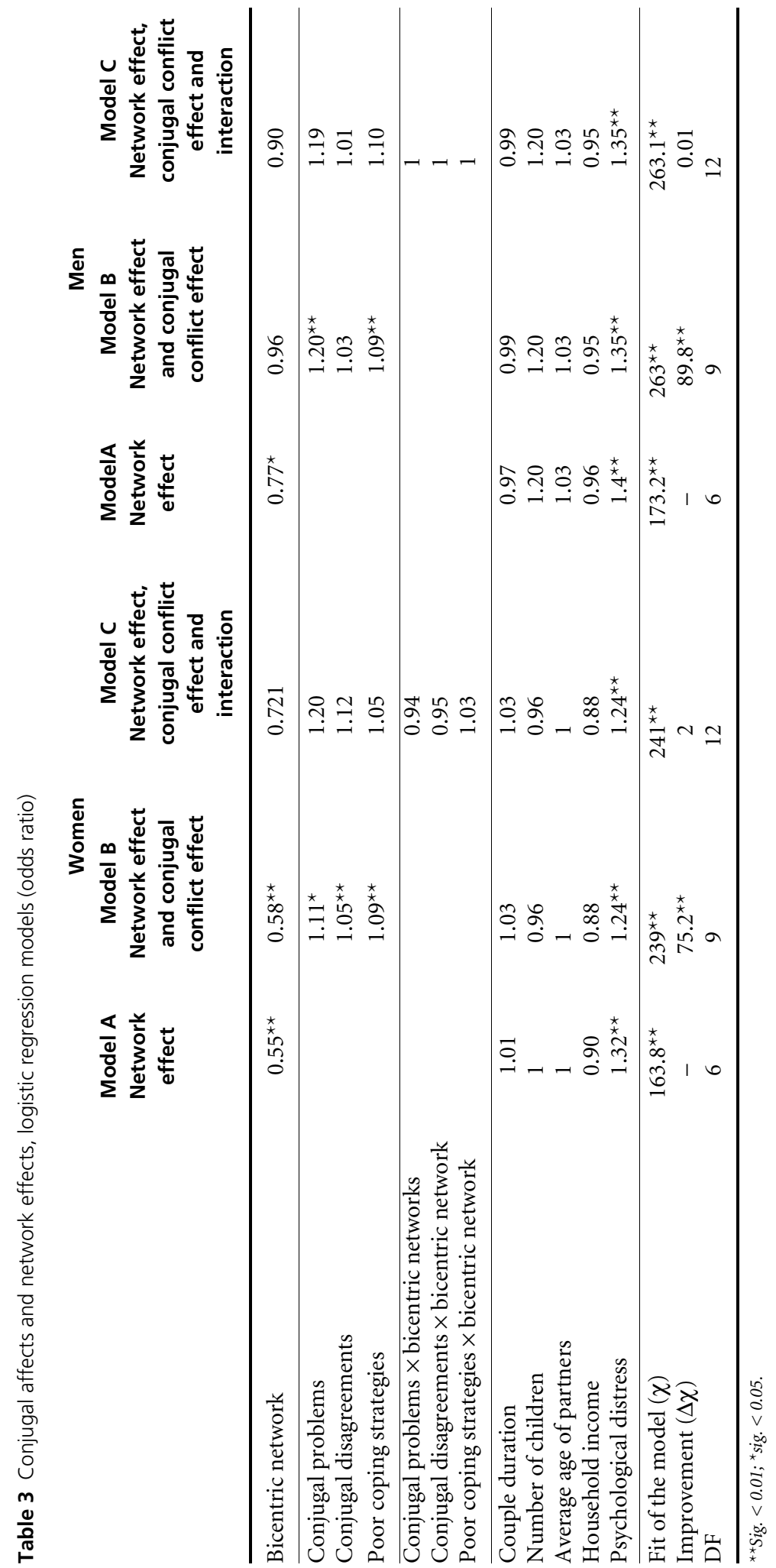


Thus, Model 3C inappropriately measures the effects of conjugal networks and conjugal conflict and Model 3B should be preferred. ${ }^{2}$ Results for conjugal dissatisfaction are shown in Table 4.

Results from Model 4A confirm that bicentric networks are associated with lower conjugal dissatisfaction than other network types. Model 4B illustrates that the effect of networks is mostly an indirect one since the coefficient for complete network effect becomes insignificant for men and marginally significant for women when indicators of conjugal conflict are included. Model $4 \mathrm{C}$ shows again that no significant interaction exists between network types and effects of conjugal conflict. Results for marital instability are considered in Table 5.

For men, results from Model 5A again confirm that bicentric networks are associated with lower conjugal instability than other types of networks. Model 5B shows that the effect of bicentric networks is indirect, as it is caused by its association with low levels of conjugal conflict. Coping strategies play a central role in this regard: if this variable is taken out of Model 5B, the network effect remains significant. No significant interaction exists between conjugal conflict and network types (Model 5C). For women, bicentric networks do not have a significant effect on conjugal instability. ${ }^{3}$

To summarize, couples with bicentric networks are better off than couples with other types of networks, in regard to the three selected indicators of conjugal quality. Unicentric networks (either patricentric or matricentric), friendship and intrusive networks are no different from sparse networks in terms of their effects on conjugal quality. Network types do not have a buffering effect between conjugal conflict and conjugal quality. Rather, results confirm the presence of an indirect effect of conjugal networks: inclusion of conjugal conflict indicators are, in all cases but one, sufficient at causing the network effect to drop to non-significance.

\section{Discussion}

Six network types adequately describe this subsample of married couples with co-resident children. Each type presents a distinct configuration of features. Sparse networks refer to couples relatively disconnected from relatives and friends, a case that was referred to as detachment (Coenen-Huther et al., 1994) or isolation (Adams, 1970; Bonvalet et al., 1999). The data also show that about one fifth of couples are more friendship- than family-oriented. Laterality is another feature that has proved to be structurally and functionally important. In about 40 per cent of cases, spouses do not have equally present and supportive networks. In 10 per cent, strong network support is associated with attempts of control and interference.

Couples with sparse networks are those which show the lowest conjugal quality. Thus, this study, based on a large and representative sample, confirms the positive effect of connections with network members on conjugal quality, for both genders. Couples with networks mostly constituted by friends have about the same odds of showing conjugal dissatisfaction and conjugal instability as couples with sparse networks. This finding might seem at first to contradict evidence showing that friends are less likely than relatives to be perceived as critics by individuals and that the presence of friends is positively correlated with personal well-being (Argyle and Furnham, 1983; Klein and Milardo, 2000). However, scholars have stressed the dramatic difference existing between friends and relatives (especially immediate kin) in terms of relationship content, friends being more active in companionshiplike relationships, and relatives being primary sources of emotional and instrumental support (Klein and Milardo, 2000). In this sense, couples that do not have relatives in their networks but only friends miss a fundamental source of support, a fact that might not be easily counterbalanced by the less intrusive style of relationships that one develops with friends. Interchangeability of friends and relatives in conjugal networks (Adams, 1970) is in this sense not straightforward, and the benefits associated with women friendships for couple functioning (Oliker, 1989) are only secondary compared with those of having supportive relatives.

Unilateral conjugal networks are not different from sparse networks in terms of conjugal quality. In other words, it is not enough for partners to have a strong personal network. Both partners need to have one in order for it to benefit the couple. Thus, one important result of this study is that contextual unbalance is critical for couple functioning. A likely explanation for this effect is that unicentric networks may increase tensions between spouses in cases of conflict because of unbalanced third parties involvement (Baumgartner, 1993; Burger and Milardo, 1995; Klein and Milardo, 2000).

The holistic approach to analysing network features permitted by cluster analysis reveals that only one configuration is systematically associated with significantly improved conjugal quality. As a matter of fact, social networks have a positive impact on conjugal quality only when they are strong for both partners, without interfering with the couple functioning. The positive effect of bicentric networks is mostly an indirect effect. In other words, integration in a bicentric network increases the 


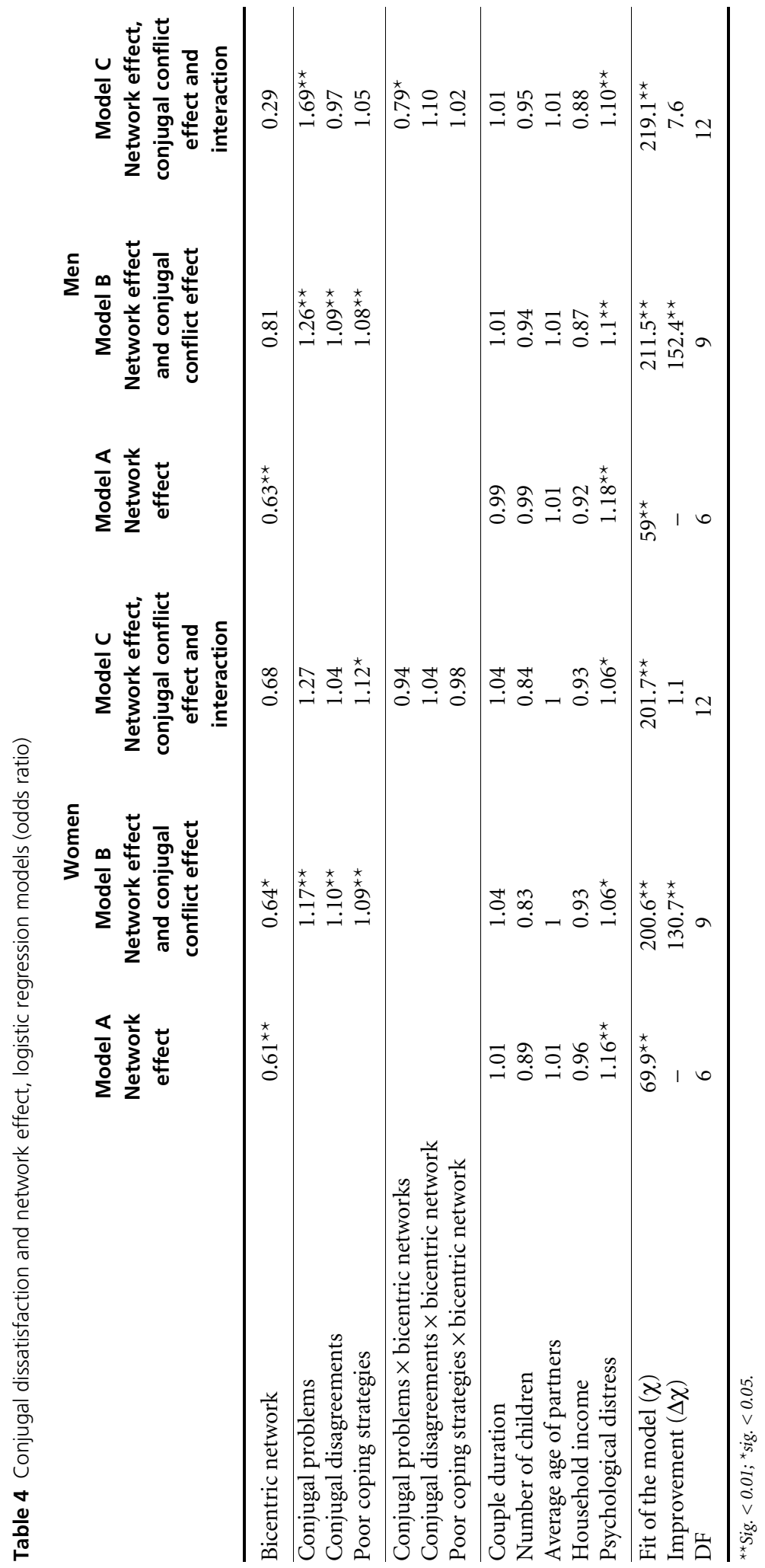




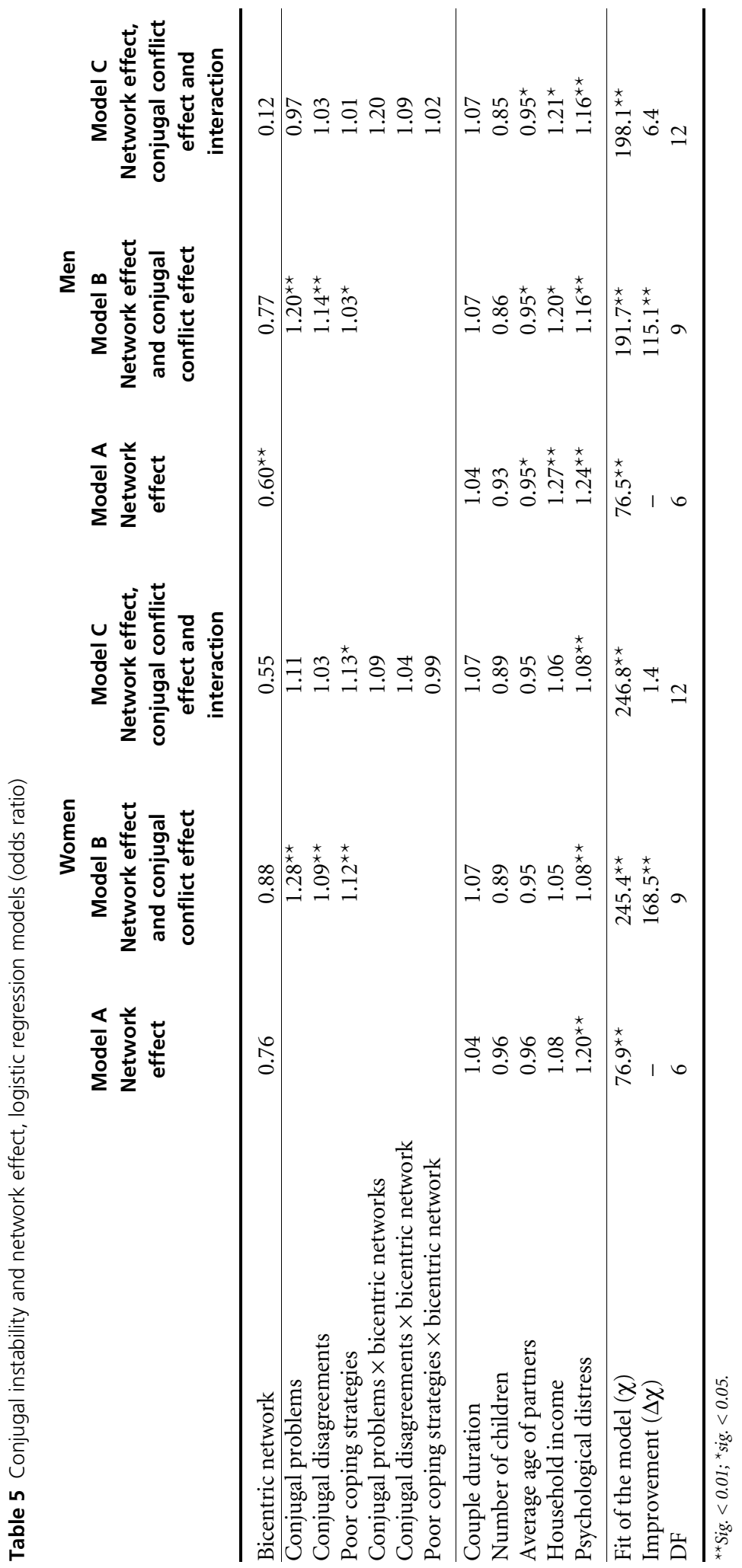


partners' likelihood of having fewer conjugal problems, conjugal disagreements and poor coping strategies, which positively affect the overall feeling toward the conjugal bond. Contrary to what is suggested by the buffering hypothesis, however, we did not find any evidence supporting the idea that conjugal networks might protect couples from the effects of an ongoing conjugal conflict on conjugal quality.

These results shed light on the mechanisms associated with the influence of conjugal networks on conjugal functioning. They suggest that conjugal networks might prevent the occurrence of poor conjugal quality in a variety of ways, such as emotional support, alternate social ties, social comparison, etc., but not in buffering the effects of conjugal conflict. The insignificance of the buffering effect can be interpreted in light of the emphasis on the couple's emotional and functional independence and the primacy of the nuclear family over other kin or non-kin ties in Western societies (Parsons, 1943; Hsu, 1965). In this sense, an explanation might be that conjugal conflict, once it has developed, is often considered as a private matter, and interventions of friends and relatives in it are equivocal.

This interpretation is confirmed by the correlation existing between interfering networks and low levels of conjugal quality. The relatively poor conjugal quality of couples with an interfering network confirms the curvilinear effect of support networks suggested by some authors (Holman, 1981; Johnson and Milardo, 1984). When networks are too involved, they are seen as interfering in the couple's functioning, and as such, they become counter-productive in terms of conjugal quality. It is important to emphasize that kinship networks are not only characterized by support and caring but also by problems and conflicts among relatives (Adams, 1970; Coenen-Huther et al., 1994). Some relationships, such as in-law relationships, are known to often be problematic (Fischer, 1983; Widmer, 1999). Those problems might stimulate and contribute to conflict between spouses, especially when interdependence among relatives is strong. Richly interconnected networks with some elements feuding with other elements become destructive for couple functioning (Broderick, 1988). For instance, intervention of third parties in an existing conjugal conflict might reinforce partners' self-legitimacy (Klein and Milardo, 2000) and therefore might make a consensual solution more unlikely.

Our results also confirm that gender differences exist regarding the effects of conjugal networks. The hypothesis that network ties are more influential on women than on men, as women report greater involvement in family activities than men, receives some confirmation here. Conjugal networks have a highly significant effect on conjugal affect and conjugal dissatisfaction for women but not for men, as they have a significant effect on conjugal instability for men but not for women. However, the mechanisms of network influences were usually the same for both genders. One exception is that tense conjugal affects are significantly lower for men with a friendship network and for women with a matricentric network.

There are several limits to this study that should be noted. First, we do not know of any equivalent multivariable typology of conjugal networks, based on a representative sample, which might help to corroborate this study's results. Most research done on networks and conjugal quality have focused on specific variables, considered independently, an approach which probably allows researchers to measure more precisely their effects but lacks the holistic view that only a typological approach permits. We plead for network typologies to be developed, bearing in mind the fruitful results provided by the typological approach of family functioning (Kantor and Lehr, 1975; Reiss, 1981; Olson et al., 1988; Olson and McCubbin, 1989). Second, the study design unfortunately does not include any indicator of network overlap between spouses, as each spouse had to define his or her network independently from the other in the questionnaire. Therefore, we do not know whether or not the proportion of joint versus separate network members varies according to the six network types revealed. Further research is needed in order to include network overlap as a distinct feature of network types.

\section{Notes}

1. From systems theory (Broderick, 1988, 1993), we hold that networks are specific configurations of attributes with emergent properties. Thus, their effects on conjugal functioning cannot be tested on a variable per variable basis, as done by variance analysis, even if including interaction terms among variables.

2. We also ran a series of alternate regression models with another coding scheme, with both bicentric and matricentric networks singled out for women, and bicentric and patricentric networks singled out for men. Results were identical.

3. Interestingly, when psychological distress is taken out of the equation, the effect of bicentric networks becomes highly significant for women as well. 


\section{References}

Adams, B. N. (1970). Isolation, function and beyond: American kinship in the 1960s, Journal of Marriage and the Family, 32, 575-597.

Allison, P. D. (1999). Comparing logit and probit coefficients across groups, Sociological Methods and Research, 28, 186-208.

Argyle, M. and Furnham, A. (1983). Sources of satisfaction and conflict in long-term relationships, Journal of Marriage and the Family, 45, 481-493.

Baumgartner, M. P. (1993). Violent networks: The origin and management of domestic conflict. In Felson, R. B. and Tedeschi, J. T. (Eds), Aggression and Violence. Washington, DC: American Psychological Association, pp. 209-232.

Bonvalet, C., Gotman, A. and Grafmeyer, Y. (1999). La famille et ses proches. L'aménagement des territoires. Paris: Presses Universitaires de France.

Bott, E. (1957). Family and social networks. London: Tavistock.

Booth, A. and Amamto, P. (1991). Divorce and psychological stress, Journal of Health and Social Behavior, 32, 396-407.

Broderick, C. B. (1988). Healing members and relationships in the intimate network. In Milardo, R. M. (Eds), Families and Social Networks. NewBury Park, CA: Sage, pp. 221-234.

Broderick, C. B. (1993). Understanding Family Process. Basics of Family Systems Theory. London: Sage.

Bryant, C. M. and Conger, R. D. (1999). Marital success and domains of social support in long-term relationships: Does the influence of network members ever end? Journal of Marriage and the Family, 61, 437-450.

Burger, E. and Milardo, R. M. (1995). Marital interdependence and social networks, Journal of Social and Personal Relationships, 12, 403-415.

Coenen-Huther, J., Kellerhals, J., von Allmen, M., Hagmann, H.-M., Jeannerat, F. and Widmer, E. (1994). Les réseaux de solidarité dans la famille, Lausanne: Réalités Sociales.

Cohen, S. and Wills, T. A. (1985). Stress, social support and the buffering hypothesis, Psychological Bulletin, 98, 310-357.

Everitt, B. S. (1993). Cluster analysis. New York: Edward Arnold.

Fischer, L. R. (1983). Mothers and mothers-in-law, Journal of Marriage and the Family, 45, 187-192.

Finchman, F. D. and Bradbury, T. N. (1987). The assessment of marital quality: A reevaluation, Journal of Marriage and the Family, 49, 797-809.

Greenacre, M. J. (1983). Theory and Applications of Correspondence Analysis. London: Academic Press.
Greenacre, M. J. (1993). Correspondence Analysis in Practice. London: Academic Press.

Holman, T. B. (1981). The influence of community involvement on marital quality, Journal of Marriage and the Family, 43, 143-149.

Hosmer, D. W. and Lemeshow, S. (1989). Applied Logistic Regression. New York: John Wiley and Sons.

Hsu, F. (1965). Kinship and Culture. Chicago: Aldine.

Jaccard, J., Turrisi, R. and Wan, C. K. (1990). Interaction Effects in Multiple Regression. NewBury Park, CA: Sage Publications.

Johnson, C. L. (2000). Perspectives on American Kinship in the later 1990s, Journal of Marriage and the Family, 62, 623-639.

Johnson, M. J. and Milardo, R. M. (1984). Network Interference in Pair Relationships: A social psychological recasting of Slater's theory of social regression, Journal of Marriage and the Family, 46, 893-899.

Julien, D., Markman, H. J., Leveille, S., Chartrand, E. and Begin, J. (1994). Networks' support and interference with regard to marriage : Disclosure of marital problems to confidants, Journal of Family Psychology, 8, 16-31.

Kantor, D. and Lehr, W. (1975) Inside the Family: Toward a Theory of Family Process. San Francisco, CA: Jossey-Bass.

Kaplan, B. H., Cassel, J. C. and Gore, S. (1977). Social support and health, Medical Care, 25, 47-58.

Klein, R. C. A. and Milardo, R. M. (2000). The social context of couple conflict: Support and criticism from informal third parties, Journal of Social and Personal Relationships, 17, 618-637.

Lebart, L., Morineau, A. and Piron, M. (1997). Statistique exploratoire multidimensionnelle. Paris: Dunod.

Milardo, R. M. (1989) Theoretical and methodological issues in the identification of the social networks of spouses. Journal of Marriage and the Family, 51, 165-174.

OFS (1998). L'enquête suisse sur la famille 94/95. Berne: Federal Statistical Office of Switzerland.

Oliker, S. J. (1989). Best Friends and Marriage. Exchange among Women. Berkeley, CA: University of California Press.

Olson, D. H. and McCubbin, H. I. (1989) Families: What Makes Them Work? Second Edition. Beverly Hills: Sage.

Olson, D.H., Lavee, Y. and McCubbin, H. I. (1988) Types of families and family response to stress across the family life cycle. In Klein, D. and Aldous, J. (Eds), Social Stress and Family Development. New York, London: Guilford Press, pp. 16-43.

Parsons, T. (1943). The kinship system of contemporary United States, American Anthropologist, 45, 22-38.

Radloff, L. S. (1977). The CES-D scale: A self-report depression scale for research in the general population, Applied Psychological Measurement, 3, 385-401. 
Reiss, D. (1981). The Family's Contruction of Reality. Cambridge, MA: Harvard University Press.

Sprecher, S. and Felmlee, D. (1992). The influence of parents and friends on the quality and stability of romantic relationships: A three-wave longitudinal investigation, Journal of Marriage and the Family, 54, 888-900.

Stein, C. H., Bush, E. G., Ross, R. R. and Ward, M. (1992). Mine, yours and ours: a configural analysis of the networks of married couples in relation to marital satisfaction and individual well-being, Journal of Personal Relationships, 9, 365-383.

Surra, C. A. (1988). The Influence of the Interactive Network on developing relationships. In Milardo, R. M. (Ed), Families and Social Networks. Newbury Park, CA: Sage, pp. 48-82.

Surra, C. A. and Milardo, R. M. (1991). The social psychological context of developing relationships: Interactive and psychological networks. In Kingsley, J. (Ed.), Advances in Personal Relationships, 3, 1-36.

Weller, S. C. and Romney, K. C. (1990). Metric Scaling. Correspondence Analysis. Newbury Park, CA: Sage.

Wellman, B. and Wortley, S. (1989). Brothers' keepers: Situating kinship relations in broader networks of social support, Sociological Perspectives, 32, 273-306.
Wethington, E. and Kessler, R. C. (1986). Perceived support, received support and adjustment to stressful life events, Journal of Health and Social Behavior, 27, 78-89.

Widmer, E. (1999). Family contexts as cognitive networks: A structural approach of family relationships, Personal Relationships, 6, 487-503.

Widmer, E., Kellerhals, J. and Levy, R. (2003). Couples contemporains: Cohésion, régulation et conflits. Une enquête sociologique. Zürich: Seismo.

\section{Authors' addresses}

Eric Widmer, Université de Lausanne, Centre PAVIE, Bátiment Provence, 1015 Lausanne, Switzerland. Email: eric.widmer@ pavie.unil.ch

Jean Kellerhals, Department of Sociology, University of Geneva, Boulevard Du Pont D'arve 40, 1204 Geneva, Switzerland.

René Levy, University of Lausanne, Centre PAVIE, Bâtiment Provence, 1015 Lausanne, Switzerland.

Manuscript received: September 2002. 
